\title{
Web Technologies and New Paradigms in Cognitive Sciences
}

\author{
Antonio Cartelli \\ University of Cassino, Italy
}

cartan@officine.it

\begin{abstract}
The paper presents the results of the analysis of the difficulties evidenced by the students while approaching some scientific disciplines (the ones the author has been teaching or involved with) and shows various kinds of these problems usually known as preconceptions, misconceptions or mental schemes in students' learning.

The work describes then the strategies adopted to help students in overcoming their difficulties by using specific strategies built up with the help of the constructivistic paradigm. It analyzes soon after the experiences made by the author while using Web techniques to support his teaching activity and proposes the model of a special Web site where e-commerce techniques have been adopted.

The paper ends with the description of the monitoring process of students' knowledge one can carry out with the above site by using the Data Base it's interfaced with and gives an outline of the possible knowledge paradigms this instrument leads to.
\end{abstract}

Keywords: Web, misconception, mental scheme, knowledge monitoring, knowledge paradigm.

\section{Introduction}

During the last century Piaget, Vygotsky, Bruner and others have founded the basis for the achievement of the cognitive perspective of knowledge against the behaviouristic one.

Further contributions to the description of knowledge construction come, among others, from Gagné, Bloom and Ausubel. It's important for what follows to remember this last researcher who proposed, with respect to the former ones, the distinction between meaningful and not meaningful learning, based on the existence of subsumers (units of previous knowledge that make an easier construction of new knowledge).

More recent studies, often under stimulation of new technologies' introduction in education (multimedia, hypertext, etc.), enriched the field of cognitive theory and gave rise to the concepts of multiple intelligence, learning styles and cognitive flexibility (Gardner 1993, Mc Lellan 1996, Spiro

Material published as part of this proceedings, either on-line or in print, is copyrighted by the author with permission granted to the publisher of Informing Science for this printing. Permission to make digital or paper copy of part or all of these works for personal or classroom use is granted without fee provided that the copies are not made or distributed for profit or commercial advantage AND that copies 1) bear this notice in full and 2) give the full citation on the first page. It is permissible to abstract these works so long as credit is given. To copy in all other cases or to republish or to post on a server or to redistribute to lists requires specific bermission from the author.
1990) to take into consideration the complexity of cognitive phenomenon.

Starting from the results of first cognitive researchers other studies proposed a constructivistic perspective for learning interpretation and knowledge construction. The main tenets of constructivism as a philosophy can be summarized as follows (Greening 2000):

- meaning is not transmitted (learning occurs as a process of adjustment of existing concepts)

- understanding is based on interaction among a complex weave of factors (i.e. the learner's goals and existing concepts, the content of the learning experience, the context in which the learning takes place, etc.)

- puzzlement motivates learning (the sense of dissatisfaction emerges from experiences that threaten existing conceptual structures)

- social negotiation and viability are the principle forces involved in the evolution and construction of knowledge.

Many hypothesis of changes in education within this new perspective come (especially in computer assisted learning) from the emphasis many researchers gave to cooperative learning, distributed cognition, situated learning and cognitive apprenticeships (Johnson 1985, Jonassen 1994, McLellan 1996, Casey 1996). 


\section{Misconceptions, Mental Schemes and Web Sites}

Since late '70s many studies carried in parallel with the previously mentioned ones paid particular attention on misconceptions and mental schemes evidenced by the students in specific scientific disciplinary fields and proposed some methods and techniques to make an easier acquisition of correct scientific concepts by the students.

It's useful to remember here, for the sake of completeness, the terms preconception and misconception are likely better used when people meet for the first time a new discipline and show wrong ideas or make mistakes while interpreting phenomena or answering specific questions (often ambiguous) during their first approach to the discipline. This early phase of study characterized by the presence of difficulties during a lapse of time that can be different for each individual has been explained in some contexts, one of which is Computer Science, with the "novice Vs expert" paradigm (Rogalsky, 1993). The words mental scheme have been used, on the contrary, to explain the presence of some wrong ideas after longer times of study or at the end of specific courses. These ideas seem to arise from the conflict between previous ideas or knowledge the students built in their everyday experience and the scientific structure of discipline concepts (in this case the wrong ideas evidenced by the students can be put in an interpretative scheme having an internal coherence).

Two case studies are presented here with their common characteristics because of the implications they have in what follows. The former one is concerned with misconceptions and mental schemes on motion and gravity (Cartelli 1984, Ruggiero 1985), the latter one with preconceptions, misconceptions and perhaps mental schemes (further studies need to be carried out to state the structure of such a mental scheme), evidenced by students while approaching Computer Science arguments, i.e. imperative and logic programming paradigms (Cartelli 1994, Cartelli 1996, Cartelli 1997).

Some common aspects characterizing the results of the above researches are listed below:

- In both cases the need for the analysis of students' concepts come from the mistakes they made while approaching the disciplines (at various school degrees, i.e. secondary or university ones), or after having attended courses of different levels on specific disciplinary aspects (and not only after a first approach to the disciplines).

- The preconceptions and misconceptions (i.e. the wrong ideas) were always evidenced by specific tests submitted to the students (answers to questions, solutions of exercises, analysis of situations) and were discussed with them (by means of interviews to the students who answered the questions in the tests).

- The analysis of students' ideas, i. e. the individuation and classification of their specific wrong ideas, needed much time (from two to three/four years) because of two reasons: a) the little samples of students involved in the research (no more than two or three classes each time, i.e. no more than 50-60 students), b) the requirement of checking the initial hypothesis concerning the students' ideas on subjects not influenced by previous inquiries.

- The preconceptions and misconceptions emerged during these studies were verified on a wide range of people (still studying or after having attended specific courses on the disciplinary fields) and led to the hypothesis of the existence of natural mental schemes influencing the students' way of thinking.

- A common strategy useful to help students in overcoming their difficulties required the creation of cognitive shocks in students' minds by means of deepen discussions about the wrong ideas they manifested on specific situations emerging from real problems, with respect to the correct ones belonging to scientific disciplines.

- In Computer Science studies, with respect to Physics ones, together with the feed-back induced by the discussions held with the students revealed very useful the strategies inherited by constructivist studies and by other researches quoted in the introduction (mostly involving the work of the students at the computer) (Cartelli 1998).

Relevant results obtained by the author while teaching Computer Programming with the experimentation of the above strategies were, among all, the good scores the students had to tests and examinations. What's more they demonstrated less sensitive to ambiguous situations, also after a lot of time. A good check for the above assertion is given by more than $75 \%$ of positive answers some students (i.e. a whole class) gave to two different tests more than a year the one from the other (Cartelli, 1996).

The above guidelines and the author's experience on misconceptions revealed very useful to solve analogous problems in a different field, i.e. in analyzing the difficul- 


\section{Web Tech and New Paradigms}

ties evidenced by some students of the Faculty of Humanities while attending the courses of Experimental Pedagogy and Social Statistics. In both disciplines, in fact, the elements of Descriptive Statistics have a significant role in the curriculum and the students showed many difficulties in understanding and applying just these notions.

When this study started more than $45 \%$ of the students didn't pass the examinations at the end of the courses because of their wrong ideas in Descriptive Statistics and the wrong answers they gave to the questions in the tests to get through at the end of the course.

Some misconceptions evidenced by the students are listed below:

1. when they construct the table of the absolute frequencies of the events concerning a phenomenon they omit every case with zero frequency;

2 . they omit all cases with zero frequencies in the graphical representation of a phenomenon and are persuaded that different units can be used to represent equal quantities;

3. while grouping in classes the events (frequencies) of a phenomenon they think the width of every class may vary (also if explicitly required all the classes have to be equal) and what's more the limits of contiguous classes may overlap;

4. they evaluate the arithmetic mean value of a set of data in several different ways (i.e. not only adding all values and dividing by the number of all values);

5. also the median value of a set of numeric data can be evaluated in several different ways.

To help the students in overcoming their difficulties some lessons were held just before the end of the courses where the analysis of specific situations were posed. The discussions undertaken with the students on their wrong ideas created the foretold cognitive shocks and revealed very useful to make them constructing the correct knowledge of the phenomenon. When sitting examinations, in fact, the $80 \%$ of the students who took part to these lessons had good scores and showed the acquiring of the correct ideas.

Unfortunately the number of students who could take advantage of this recovery action was relatively small. Many other students, in fact, couldn't take part to the didactic activity for different reasons such as: the distance of the towns they come from (they were commuters and every day at the end of the lessons went back home), the overlapping of the lessons of the courses, etc.
The hypothesis of an hypertext to simulate the discussions held during the courses and the creation of a Web site appeared very soon the best solution to help the last set of students.

The reasons for the above hypothesis can be summarized as follows:

1. Web pages can be used to simulate the analysis of a situation by means of the tree structure of the hypertext

2. every student while browsing the site and selecting the items analyzes or re-analyzes the situation under observation (while being alone or not)

3. a good design of the Web site and self-assessment tests within it can cause a reinforcement action for disciplinary correct ideas

4. CMC (Computer Mediated Communication) researches have shown the Net (and its communication services) can be used to create on-line communities having features very similar to the real ones (virtual places where sharing knowledge), thus producing collaborative learning effects that can balance the absence of a teacher/tutor moderating the discussion.

The main problem in the site design was given by the individuation of the information units to put in a page (i.e. the nodes in the hypertext tree) for two reasons:

a) to make unambiguous the knowledge tree represented by the site (if too many information were collected in the same page)

b) don't fragment too much the knowledge's units (if different portions of the same information appeared in more than a page)

A solution come from the analysis of the students misconceptions :

- great attention was devoted, with respect to the usual top-down design of a site, to the creation of pages better describing the themes strongly related to specific misconceptions

- self-assessment tests with closed answers were also used; the choice of a wrong answer leading to the reanalysis of the Web page with the corresponding theme

Other tricks adopted to obtain a fair attention from the students while browsing the site resided in some icons, lent by e-mail smilies (little faces made up with punctuation signs), and in a two color text used to emphasize the differences between the wrong and the correct answers to the questions. 


\section{A. Cartelli}

A mail-list was also made up to allow the students putting questions to professors or exchanging information among themselves (Cartelli 2000).

The adoption of solutions at no cost revealed equally important for the realization of the Web site within the Faculty (that is linked to Internet). An old 486 Intel PC was chosen as server and software freely accessible on the Net was adopted: i.e. Linux (kernel rel. 2.0.36) was the OS and the package Apache (rel. 1.3.6) the Web server. The pages of the Web site were edited by nothing more than a system editor (mainly vi) and the images were created and manipulated by the Gimp.

The structure of this first site can be easily described.

From the home page a student could access a list of situations to examine. For each of the problems listed in that page there was a link to another page where the corresponding situation was analyzed in detail and various questions were posed. For every question there were some answers (the correct one and the wrong ones emerged during the discussions with the students) and for each of them there was a link to another page. In this last page the students could find the explanation of their proper or less proper answers and could reach the page of the lesson with the correct description of the phenomenon.

Before the site was made available it was tested with some students who expressed appreciation for its kindness but, at the same time, it soon appeared the fair limit of the site was the lack of feedback. If it's true the students could take advantage of the Web site browsing there was no evidence or information on their alternative hypothesis (if some idea different from the proposed ones could be present) and their learning styles (i.e. their way of approaching the situations and the arguments).

To satisfy the above requirements the author decided to create a Data Base to interface with the Web site because

1. It's very easy to build up a Web Chat to let the students communicate each other and store every message they send each other

2. It's possible to acquire answers to open questions and store them

3. It's possible to store every information on students' browsing, i.e. every page they visit (thus observing their learning styles)

4. It's possible to monitor the students' learning processes

5. Information stored in the data base can be ordered, selected, retrieved in any way
The interface of the site with the Data Base was made possible by accompanying the creation of HTML pages with two tools: a DBMS (Relational and supporting the SQL language) and a front end system for it (to be used together with FORM pages to transmit data, queries, etc. to the Web server and then to the DBMS). After a short research on the Net the tools Postgres (rel. 6.5) and Php (rel. 3.0.11) were chosen. The former is a Relational DBMS, it uses SQL to manage tables and data and interfaces well with various languages $(\mathrm{C}, \mathrm{C}++$, Perl, Tcl, $\mathrm{Php}$, etc $)$, the latter is a real programming language (derived from Perl) and can be built as a module within the Apache web server. These packages and the systematic use of HTML FORMS (this technique is widely used in e-commerce sites) allowed to send data to Postgres DBs and to store and retrieve any information concerning student's movement within the site.

The adoption of the packages and of the techniques described above forced the conversion of the HTML pages in PHP pages. Furthermore the same instruments allowed the creation of a Web Chat to increment the opportunities of communication among students (they like it much more than e-mail). Four tables have been created within the database (see Fig. 1): the first one has been devoted to the students' data (the ID no. of the students was chosen as the primary key), the second one can store the students' routes among the pages (it stores the code of the page visited by a student, his primary key and the access time), the third table can be used to collect possible answers different from

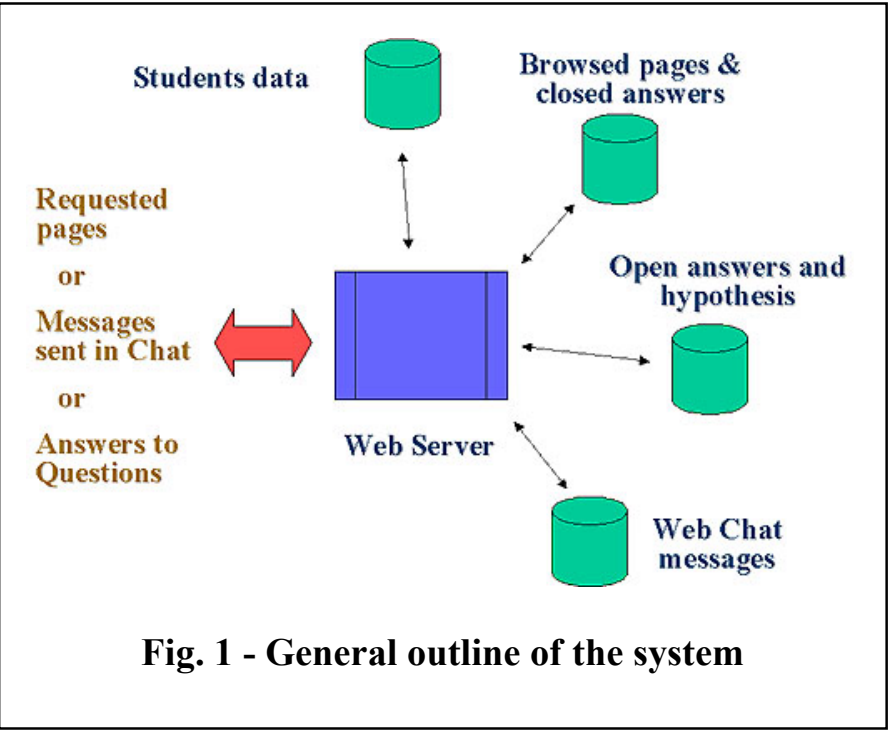

the ones gathered by the tests and the last one reports the messages sent to the chat. 


\section{Web Tech and New Paradigms}

Another characteristic of this new site is the partition of the accesses into two parts: the former one is opened to the students and lets them browsing the site and using all the communication services (after they have been recognized and authorized to access the site), the latter one can be accessed only by professors and lets them to retrieve every information on students' access to the site.

\section{Towards New Paradigms}

The first relevant consideration one can draw from what has been said till now concerns the synergy the present study has created among pedagogical inquiry techniques, hypertext design and web techniques. With respect to other experiences of computer use in education, in fact, the following elements have to be noted:

- the educational site emerges from didactics' researches and not from a discipline teaching project (in other words there is a bottom-up more than a top-down analysis of the site requirements)

- the hypertext project and the individuation of the level of elements break up within the 'discipline knowledge tree' come from the answers of the students to the tests and from the analysis of their ideas, more than from the logic structure of the discipline

The above aspects induce to re-consider the role of Computer Science and Web techniques. They are asked in fact to develop new instruments for making the didactic research more efficient in investigation and interpretation of knowledge processes.

From a pedagogical and psychological perspective we can look at the integrated system Web-DBMS from two different viewpoints: on one side it is an instrument for giving support to everyday teaching work and helping students in overcoming their difficulties, on another side it can be seen as a diagnostic instrument because it can show the students' cognitive processes evolution in a single discipline and in a more general way (i.e. very similar to what happens with Computerized Tomography in Medicine).

Other consequences of the use of the Web-DBMS integrated systems can be found in Computer Assisted Learning projects and perhaps in ITS. During the last decade, in fact, many experiences with ITS had results less positive than the expected ones due to the rigidity of the students' models they adopted; with the help of the system proposed here it will be possible to have more accurate information on students' thinking and better models might be hypothesized for future projects.
Another consideration emerges from the analysis of Cohen definition of Informing Science (Cohen 1999) and leads to the question: - Are there the premises to talk of a new paradigm in educational sciences? -. As reported by Cohen in fact "The fields that comprise the discipline of Informing Science provide their clientele with information in a form, format and schedule that maximizes its effectiveness" and "The Informing Science Framework has three components: the informing environment, the delivery system and the task-completion system". We can recognize in our context all the previous elements: the task-completion system can be seen in the need of individuation of natural mental schemes evidenced by the students and in the need of a greater efficiency in the didactic activity, the delivery system has its elements in inquiry techniques and information technologies, the informing environment is made by people needing information in different forms, levels of detail and sequences: students and researchers are two examples of these people. But previous observations are enough to assert that Informing Science can be considered as a Pedagogical Science like Psychology, Sociology, Anthropology, Biology, Cybernetics, etc.? What are the implications for Didactics, the discipline studying the learning processes? Is there a component of Informing Science within it or, on the contrary, is it a field of Informing Science?

Many other researches need to be carried out to give an answer to the above questions but, what's more, a new conceptualization of electronic medium influence on the construction of new knowledge imposes to our attention. It's well known in fact the pedagogical knowledge lies on qualitative and quantitative methods that are, to cite only some of them, the experimental one, the autobiographical one, the comparative one, the hermeneutical one etc. How much these methods are affected by electronic medium and particularly by the integrated system the author proposes here?

It's in the authors' opinion there are at least two different viewpoints answering to the above question, the one opposite to the other: the former one seeing in the Web technologies the instruments to simplify and make quick and fast the operations usually made by scholars and researchers, that nothing new add to well consolidated methods and strategies; the latter one characterizing people with good skill in on line communication techniques and practices, seeing in the Web techniques an instrument for acquiring and constructing new scientific knowledge. 
This last viewpoint leads to a new knowledge paradigm defined by the author as on line knowledge. The requirement of a new definition comes from the different aspects other definitions dwell upon while analyzing communication-knowledge processes taking place on the Net and particularly on the Web. A first attempt of defining the on line knowledge that is concise but exhaustive can be the following one: it's the process leading to new knowledge made up by previous knowledge by means of all synchronous and asynchronous communication services available on the Net (and particularly the Internet). Concrete and consolidated examples of this paradigm can be found in the experiences of Net communities working to software projects like the Apache group, the Linux Users Group, the GNU project etc. .

The author wishes more and more pedagogists, teachers and educators will discover and adopt as soon as possible this new paradigm thus extending their ways of understanding learning phenomena and knowledge construction processes.

\section{Conclusion}

In the first section of this work after a short description and analysis of the studies on conceptualization the author has presented the results of some researchers on misconceptions and mental schemes evidenced by the students while approaching new scientific disciplines.

He has then illustrated the evolution of a Web site designed to help students in overcoming their difficulties and has proposed the on line knowledge paradigm to interpret the different ways one can use to build new knowledge in the field of pedagogical sciences.

It's important to remark the same author is persuaded the automatic extension of his hypothesis to all the people involved in pedagogical researches is very difficult because of the presence of serious troubles and doubts in the acquisition of this new paradigm by many scholars and researchers.

If a "human factor" operates against the adoption and diffusion of the on line knowledge paradigm it's too early to say but it's in the author's opinion the problems one can meet in the use of this paradigm can be attributed to the current way of seeing knowledge as hierarchically organized and partitioned into disciplines and sub-disciplines, each one with a specific field of investigation well characterized and distinct from the others. From different sources has been posed in fact the problem of the need of a reconceptualization of knowledge to face the challenges of today complexity.

\section{References}

Cartelli, A. \& Ruggiero, S. (1984). Il ragionamento spontaneo in ragazzi di terza media: il concetto di forza e gli schemi di moto, Proceedings of the "XXIII Congresso Nazionale dell'AIF", Gaeta (LT), Italy, 101-110.

Cartelli, A. (1994). Misconcetti e schemi alternativi in Informatica. Proceedings of "DIDAMATICA '94, 10th Meeting on Computer Science for Didactics (scientific papers)", held by GdL "Applicazioni degli elaboratori alla Didattica" of AICA, Cesena (FO), Italy, 87-102.

Cartelli, A. (1996). Analisi di alcuni schemi mentali in studenti di Informatica. Proceedings of "DIDAMATICA '96, 11th Meeting on Computer Science for Didactics (scientific papers)", held by GdL "Applicazioni degli elaboratori alla Didattica" of AICA, Cesena (FO), Italy, 64-78.

Cartelli, A. (1997). Alcune indicazioni di carattere metodologico nell'insegnamento dei paradigmi di programmazione. Proceedings of "DIDAMATICA '97, 12th Meeting on Computer Science for Didactics (scientific papers)", held by GDL "Applicazioni degli Elaboratori alla Didattica" of AICA, Siena, Italy, 133-139.

Cartelli, A. (1998). Linux e didattica. Work presented at Pluto Meeting Linux Meeting '98, Conference organized by Pluto Journal and LUG - Roma, with the sponsorship of IEEE student branch "La Sapienza" - Rome, accessible on the Web syte of the Faculty of Humanities at University of Cassino - Italy:

\section{ettp./Tww.tet.unicas.it/ricerca/cartans.ntm}

Cartelli, A. \& Ruggiero, S., (2000). Misconcetti e Web: un sito dedicato all'autovalutazione ed all'autoapprendimento. Proceedings of "DIDAMATICA 2000, 13th Meeting on Computer Science for Didactics (scientific papers)", held by GDL "Applicazioni degli Elaboratori alla Didattica" of AICA, Cesena (FO), Italy, 123-133.

Casey C. (1996). Incorporating cognitive apprenticeship in multimedia. Educational Technology Research and Development, 44 (1) 71-84.

Cohen E. (1999). Reconceptualizing Information Systems as a Field of The Transdiscipline Informing Science: From Ugly Ducking to Swan, Journal of Computing and Information Technology. 7 (3), 213-219

Gardner, H. (1993). Multiple intelligences: The theory in practice. New York: Basic Books.

Johnson, R. T., Johnson, D. W. \& Stanne, M. B. (1985). Effects of cooperative, competitive, and individualistic goal structures on computer assisted instruction. Journal of Educational Psychology, 77 (6) 669-677. 


\section{Web Tech and New Paradigms}

Jonassen, D. H. (1994). Learning with media: Restructuring the debate. Educational Technology Research and Development, 42 (2) 31-39.

Mc Lellan, H. (1996). Being digital; Implications for education. Educational Technology, November/December 5-20.

Rogalski, J. \& Samurçay, R. (1993). Task Analysis and Cognitive Models as a Framework to Analyze Environments for Learning Programming, in Proceedings of the NATO Advanced Research Workshop on Cognitive Models and Intelligent Environments for Learning Programming, New York: Springer-Verlag, 111, 1993, 6.

Ruggiero, S., Cartelli, A., Dupré, F. \& Vicentini-Missoni, M. (1985). Weight, Gravity and Air Pressure : Mental Representations by Italian Middle School Pupils. European Journal of Science Education (Eur. J. Sci. Educ.), VII (2), 181-194.
Spiro, R. J. \& Jehng, I. C. (1990). Cognitive flexibility and hypertext: Theory and technology for the non nonlinear and multidimensional transversal of complex subject matter. In D. Nix \& R. Spiro (Eds.) Cognition, Education, and Multimedia (pp. 163-205) Hillsdale NJ: Lawrence Erlbaum.

\section{Biography}

Antonio Cartelli is a teacher of CS (i.e. European I.T.) in an Italian Technical High School and has a yearly contract for teaching Educational Technologies at the Faculty of Humanities in the University of Cassino - Italy. A. Cartelli is also administering the Network Services in the same Faculty and has authored more than 10 papers on the subjects of conceptualization, misconceptions and mental schemes in different disciplines. 